\title{
The effect of low concentrations versus high concentrations of local anesthetics for labour analgesia on obstetric and anesthetic outcomes: a meta-analysis L'effet de la concentration d'anesthésique local pour l'analgésie
du travail obstétrical sur les pronostics obstétricaux et
anesthésiques: une méta-analyse
}

\author{
Pervez Sultan, MBChB • Caitriona Murphy, MBBCh •
}

Stephen Halpern, MD $\cdot$ Brendan Carvalho, MBBCh

Received: 8 November 2012 / Revised: 13 June 2013 / Accepted: 13 June 2013 / Published online: 8 August 2013

(C) Canadian Anesthesiologists' Society 2013

\begin{abstract}
Introduction The influence that different concentrations of labour epidural local anesthetic have on assisted vaginal delivery (AVD) and many obstetric outcomes and side effects is uncertain. The purpose of this meta-analysis was to determine whether local anesthetics utilized at low concentrations (LCS) during labour are associated with a decreased incidence of AVD when compared with high concentrations (HCs).
\end{abstract}

Methods We searched PubMed, Ovid EMBASE, Ovid MEDLINE, CINAHL, Scopus, clinicaltrials.gov, and Cochrane databases for randomized controlled trials of labouring patients that compared LCs (defined as $\leq 0.1 \%$

Author contributions Pervez Sultan, Caitriona Murphy, Stephen Halpern, and Brendan Carvalho made substantial contributions to the conception and design of the study and were involved in drafting the article for important intellectual content.

P. Sultan, MBChB ( $\square)$

Department of Anaesthesia, University College Hospital,

235 Euston Road, London NW1 2BU, UK

e-mail: p.sultan@doctors.org.uk

C. Murphy, MBBCh

Sunnybrook Health Sciences Centre, Department of Anesthesia,

University of Toronto, Toronto, ON, Canada

\section{S. Halpern, MD}

Sunnybrook Health Sciences Centre, Department of Anesthesia,

Obstetrics and Gynecology, University of Toronto,

Toronto, ON, Canada

B. Carvalho, MBBCh

Department of Anesthesia, Stanford University School of

Medicine, Stanford, CA, USA epidural bupivacaine or $\leq 0.17 \%$ ropivacaine) of epidural local anesthetic with HCs for maintenance of analgesia. The primary outcome was AVD and secondary outcomes included Cesarean delivery, duration of labour, analgesia, side effects (nausea and vomiting, motor block, hypotension, pruritus, and urinary retention), and neonatal outcomes. The odds ratios (OR) or weighted mean differences (WMD) and $95 \%$ confidence intervals $(C I)$ were calculated using random effects modelling. An OR $<1$ or a WMD $<0$ favoured LCs. Results Eleven studies met our criteria (eight bupivacaine and three ropivacaine studies), providing 1,145 patients in the LCs group and 852 patients in the HCs group for analysis of the primary outcome. Low concentrations were associated with a reduction in the incidence of $A V D(O R=0.70 ; 95 \% C I$ 0.56 to $0.86 ; P<0.001)$. There was no difference in the incidence of Cesarean delivery (OR 1.05; 95\% CI 0.82 to 1.33; $P=0.7$ ). The LCs group had less motor block (OR 3.9; 95\% CI 1.59 to 9.55; $P=0.003$ ), greater ambulation (OR $2.8 ; 95 \%$ CI 1.1 to $7.14 ; P=0.03)$, less urinary retention $(O R$ $0.42 ; 95 \%$ CI 0.23 to $0.73 ; P=0.002)$, and a shorter second stage of labour (WMD -14.03; 95\% CI -27.52 to -0.55 ; $P=0.04)$ compared with the HCs group. There were no differences between groups in pain scores, maternal nausea and vomiting, hypotension, fetal heart rate abnormalities, five-minute Apgar scores, and need forneonatal resuscitation. One-minute Apgar scores $<7$ favoured the HCs group (OR 1.53; 95\% CI 1.07 to $2.21 ; P=0.02)$, and there was more pruritus in the LCs group (OR 3.36; 95\% CI 1.00 to 11.31; $P=0.05$ ).

Conclusion When compared with HCs of local anesthetics, the use of LCs for labour epidural analgesia reduces the incidence of AVD. This may be due to a 
reduction in the amount of local anesthetic used and the subsequent decrease in motor blockade. We therefore recommend the use of LCs of local anesthetics for epidural analgesia to optimize obstetric outcome.

\section{Résumé}

Objectif Nous connaissons mal l'influence de différentes concentrations d'anesthésique local pour la péridurale du travail obstétrical sur l'accouchement vaginal assisté (AVA) ainsi que sur de nombreux pronostics obstétricaux et effets secondaires. L'objectif de cette méta-analyse était de déterminer si les anesthésiques locaux utilisés à de faibles concentrations (FC) pendant le travail obstétrical étaient associés à une incidence réduite d'AVA par rapport à des concentrations élevées (CE).

Méthode Nous avons fait des recherches dans les bases de données PubMed, Ovid EMBASE, Ovid MEDLINE, CINAHL, Scopus, clinicaltrials.gov et Cochrane pour en tirer les études randomisées contrôlées portant sur des patientes en travail obstétrical et comparant des FC (définies comme étant $\leq 0,1 \%$ de bupivacaïne ou $\leq 0,17 \%$ de ropivacaïne en péridurale) d'anesthésique local péridural à des CE pour le maintien de l'analgésie. Le critère d'évaluation principal était l'AVA, et les critères secondaires comprenaient l'accouchement par césarienne, la durée du travail obstétrical, l'analgésie, les effets secondaires (nausées et vomissements, bloc moteur, hypotension, prurit et rétention urinaire), et l'état du nouveau-né. Les rapports de cotes (RC) ou différences moyennes pondérées (DMP) et les intervalles de confiance (IC) à $95 \%$ ont été calculés à l'aide d'un modèle à effets aléatoires. Un $R C<1$ ou une DMP $<0$ ont été considérés comme favorisant les $F C$.

Résultats Onze études respectaient nos critères de sélection (huit études sur la bupivacaïne et trois sur la ropivacaïne), donnant un total de 1145 patientes dans le groupe FC et de 852 patientes dans le groupe CE pour l'analyse de notre critère d'évaluation principal. Les faibles concentrations ont été associées à une réduction de l'incidence d'AVA (RC=0,70; IC $95 \%$ 0,56 à 0,86; $P<0,001)$. Aucune différence dans l'incidence d'accouchement par césarienne n'a été observée (RC 1,05; IC $95 \%$ 0,82 à 1,33; $P=0,7)$. Dans le groupe $F C$, on a observé une incidence moindre de blocs moteurs (RC 3,9; IC $95 \%$ 1,59 à 9,55; $P=0.003)$, une meilleure ambulation (RC 2,8; IC $95 \% 1,1$ à 7,$14 ; P=0,03)$, une rétention urinaire moindre ( RC 0,42; IC $95 \%$ 0,23 à 0,73; $P=0,002$ ) et un deuxième stade de travail obstétrical plus court (DMP -14,03; IC $95 \%-27,52$ à $-0,55 ; P=0,04)$ que dans le groupe $C E$. Aucune différence n'a été observée entre les groupes en matière de scores de douleur, de nausées et vomissements maternels, d'hypotension, d'anomalies de la fréquence cardiaque fatale, de scores Apgar à cinq minutes, et de besoin de réanimation néonatale. Les scores Apgar $<7$ à une minute se retrouvaient davantage dans le groupe CE (RC 1.53; IC $95 \%$ 1.07 à 2.21; P = 0.02), et on a observé plus de prurit dans le groupe FC (RC 3,36; IC $95 \%$ 1,00 à 11,31; $P=0,05)$.

Conclusion Par rapport à des CE d'anesthésiques locaux, l'utilisation de FC pour l'analgésie péridurale du travail obstétrical réduit l'incidence d'AVA. Cela pourrait être lié à une réduction de la quantité d'anesthésique local utilisée et à la réduction subséquente du bloc moteur. C'est pourquoi nous recommandons l'utilisation de FC d'anesthésiques locaux pour l'analgésie péridurale pour optimiser le pronostic obstétrical.

Epidural drug administration is regarded as the gold standard for labour analgesia, resulting in improved pain and maternal satisfaction scores when compared with other techniques. ${ }^{1-4}$ Nevertheless, labour epidural analgesia may be associated with side effects, including prolonged labour, increased incidence of assisted vaginal delivery (AVD), ${ }^{4,5}$ reduced ability to ambulate, ${ }^{6}$ pruritus, ${ }^{7}$ hypotension, ${ }^{8}$ requirement for urinary catheterization, ${ }^{9}$ and abnormal fetal heart rate. ${ }^{10}$ Limiting the dose of local anesthetic and use of adjuvant drugs, such as opioids and epinephrine, may potentially reduce these side effects.

The Comparative Obstetric Mobile Epidural Trial (COMET) showed a reduced AVD rate with a low-dose epidural infusion $(0.1 \%$ bupivacaine) when compared with a higher dose $(0.25 \%$ bupivacaine $){ }^{5}$ In contrast to the COMET study, a number of other studies have shown no difference in AVD. ${ }^{11-14}$ These studies differed in the local anesthetic utilized, the concentrations of local anesthetic solution, or the varying combinations of bolus and/or continuous background infusion rates. Although the COMET study showed that the concentration of local anesthetic had an effect on AVD in nulliparous women, it was performed in only two tertiary delivery centres within the U.K., which may limit the broad generalizability of their findings to other obstetric populations and practices within and outside the U.K. A recent review by Loubert et al. highlighted the need for further studies to elucidate the impact of epidural solutions and regimens on outcomes such as the rate of AVD and the duration of labour. $^{15}$

The primary aim of this meta-analysis was to investigate whether labour epidural local anesthetic regimens utilizing low concentrations (LCs) $(\leq 0.1 \%$ bupivacaine or an equivalent ropivacaine concentration) decrease the incidence of AVD (ventouse or forceps-assisted vaginal delivery) when compared with higher concentrations (HCs) of 
local anesthetic without compromising analgesia. Secondary outcomes included obstetric outcomes, maternal outcomes, maternal side effects, and neonatal outcomes.

\section{Methods}

For this meta-analysis, we sought randomized controlled trials comparing LCs of local anesthetics with HCs for maintenance of epidural analgesia in labouring women. Low concentrations were defined as $\leq 0.1 \%$ bupivacaine or an equipotent concentration of ropivacaine $(\leq 0.17 \%) .^{16,17}$ There is no universally accepted concentration that is regarded as a low concentration. We decided to use $>0.1 \%$ bupivacaine as our cut-off value for high concentration because this value is utilized in many randomized controlled studies, including the largest trial (COMET) to represent HCs of epidural solution.

We conducted a literature search with no language restriction on August 20, 2011 and repeated the search on February 6, 2012. Searches were performed in PubMed (1950 to February 2012), Ovid EMBASE (1970 to August 2011), Ovid MEDLINE (1950 to August 2011), Scopus (1960 to February 2012), EBM Reviews Cochrane Central Register of Controlled Trials 2nd Quarter 2011, clinicaltrials.gov, and CINAHL (August 2011). Finally, we attempted to reduce publication bias by consulting the clinical trials registry (www.clinicaltrials.gov) on April 23, 2012. The search strategy consisted of a combination of subject headings (obstetric, labour, epidural) and keywords/ key phrases (bupivacaine, ropivacaine, labour, delivery, birth and trial) for each of MEDLINE, EMBASE, and CINAHL searched in specified fields (such as $t i=$ title) $a b=a b s t r a c t)$. In the event that a database did not index articles, we conducted keyword searching in the entire record (see Appendix 1 for detailed PubMed search criteria; other search strategies are available from the authors).

Reference lists of all identified studies were checked as well as those of previous meta-analyses on the same topic. All neuraxial techniques used to initiate the block (combined spinal-epidural (CSE), epidural) and different methods of administration (patient-controlled epidural analgesia, continuous epidural infusion, and clinician epidural topups) were considered. We included studies comparing groups that consistently utilized either LCs or HCs of epidural local anesthetics to establish and maintain labour analgesia, and we included studies with variations in opioid use between groups. Studies were excluded if they utilized epinephrine, administered HCs of local anesthetic to initiate analgesia and maintained analgesia with LCs of local anesthetics, or did not evaluate outcomes related to maintenance of labour analgesia with an epidural regimen. We did not exclude studies that used HCs of local anesthetics for rescue analgesia. Attempts were made to contact the original authors for additional data when required.

The quality of studies included in the meta-analysis was reviewed using the Cochrane Collaboration's tool for assessing risk of bias. ${ }^{18}$ Areas of methodological quality assessed included concealment of allocation, random sequence generation, blinding of the assessors and participants, and accounting for all subjects. We did not assess reporting bias (selective reporting of outcomes). Overall quality was graded as low (low risk of bias), high (high risk of bias), or unclear risk of bias for each domain entry using a standardized tool. ${ }^{18}$ At least two individuals extracted the study data independently utilizing a standardized review protocol and recorded the information on a data collection sheet (Appendix 2). Differences were resolved by reexamination of the original manuscripts and by discussion. The data were then entered into a computer by one of the authors (C.M.) and checked by a second investigator (P.S.).

The primary outcome was the incidence of AVD. Secondary outcomes included 1) obstetric outcomes (incidence of spontaneous vaginal delivery [SVD], rate of Cesarean delivery, duration of first and second stages of labour); 2) maternal outcomes (analgesia - worst pain score measured from 0-100 after three hours of epidural infusion), total dose of epidural local anesthetic utilized, number of interventions required by the anesthesia care providers, maternal satisfaction scores, no motor block (Bromage scores $=0$ ), and maternal ambulation during labour; 3) maternal side effects (nausea and vomiting, hypotension, pruritus, and urinary retention); and 4) neonatal outcomes (Apgar scores $>7$ at one and five minutes, fetal heart rate, umbilical cord blood gas values, and requirement for neonatal resuscitation).

Data were analyzed using Review Manager 5.1 (Review Manager (RevMan) Version 5.1. Copenhagen: The Nordic Cochrane Centre, The Cochrane Collaboration, 2011). ${ }^{19}$ For dichotomous outcomes, the odds ratio (OR) and $95 \%$ confidence interval (CI) were calculated (an $\mathrm{OR}<1$ favoured LCs). The risk difference and number needed to treat were calculated for the primary outcome. In addition, risk difference and number needed to harm were calculated for dichotomous side effects. For continuous data, the weighted mean difference (WMD) and 95\% CI were determined. The percentage of heterogeneity was assessed with the $\mathrm{I}^{2}$ statistic. A $P$ value $<0.05$ was considered statistically significant. All data were combined and analyzed using the DerSimonianLaird random effects model.

\section{Results}

The flow diagram of the study selection is provided in Fig. 1. Fifteen articles met our inclusion criteria (12 bupivacaine 
Fig. 1 Flow diagram outlining meta-analysis search
1313 articles identified

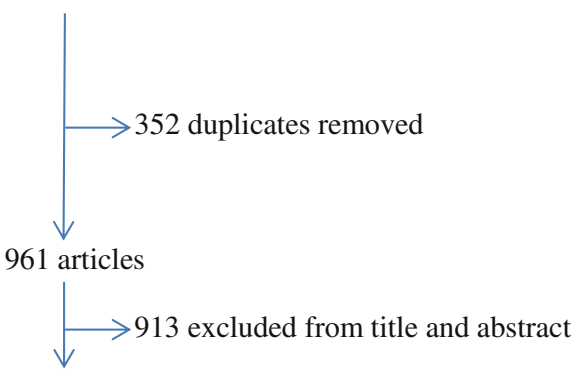

53 Articles retrieved for further review(5, 6, 9, 20-32, 38-73)

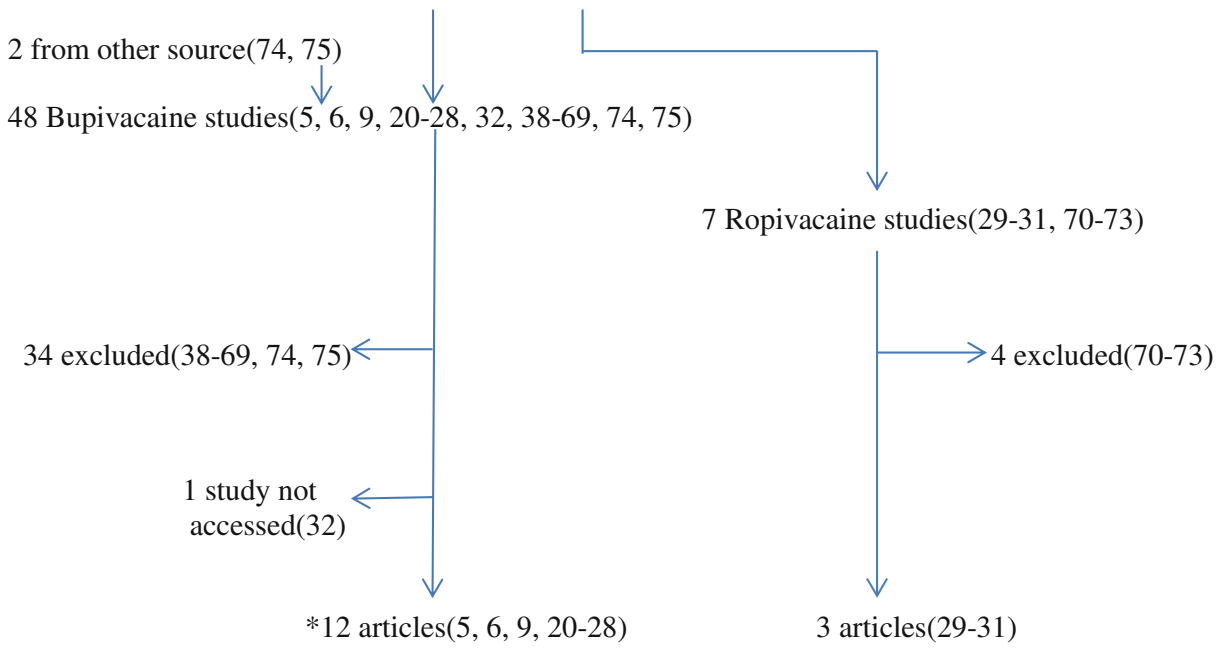

*5 publications from COMET trial grouped as 1 study $(5,6,9,20,21)$ (therefore 8 bupivacaine studies)

11 studies met the inclusion criteria ( 8 bupivacaine and 3 ropivacaine) articles ${ }^{5,6,9,20-28}$ and three ropivacaine articles). ${ }^{29-31}$ The five publications from the COMET study group were presented as one study. ${ }^{5,6,9,20,21}$ One manuscript was not available and was therefore excluded. ${ }^{32}$ Consequently, 15 articles (11 studies) involving 1,145 patients in the LCs group and 852 patients in the HCs group were analyzed for our primary outcome. The study demographics and risk-of-bias assessments are shown in the Table and Fig. 2. Excluded studies are listed in Appendix 3.

\section{Assisted vaginal delivery}

Eleven studies recorded assisted vaginal delivery as an outcome. Figure 3 shows the combined data for this outcome. Assisted vaginal delivery was reduced in the LCs group with a pooled OR of 0.70 (95\% CI 0.56 to 0.86 ; $P<0.001)$. There was negligible heterogeneity $\left(\mathrm{I}^{2}=0 \%\right.$; $P=0.47)$. The pooled risk difference was -0.07 (95\% CI -0.11 to $-0.04 ; P<0.001)$ yielding a number needed to treat of 14 (95\% CI 9 to 25$)$.
Other obstetric outcomes

Obstetric outcomes are summarized in Fig. 4. The duration of the second stage of labour favoured the LCs group (WMD $-14.03 ; 95 \% \mathrm{CI}-27.52$ to $-0.55 ; P=0.04$ ). There was no difference in the incidence of Cesarean delivery or first stage labour between the groups (Fig. 4).

\section{Maternal outcomes and side effects}

Maternal outcomes are summarized in Fig. 5, and maternal side effects are presented in Fig. 6. Labour pain (defined as worst pain score as measured by a visual or verbal analogue scale of 0 to 100) after three hours of epidural insertion was not different between groups (WMD -0.71 ; $95 \% \mathrm{CI}-6.30$ to $4.89 ; P=0.80)$. It is noteworthy that the COMET study ${ }^{5}$ could not be included in this outcome because the authors did not report a measure of dispersion. The total dose of local anesthetic administered was lower in the LCs group (WMD -27.00; 95\% CI -35.22 to 


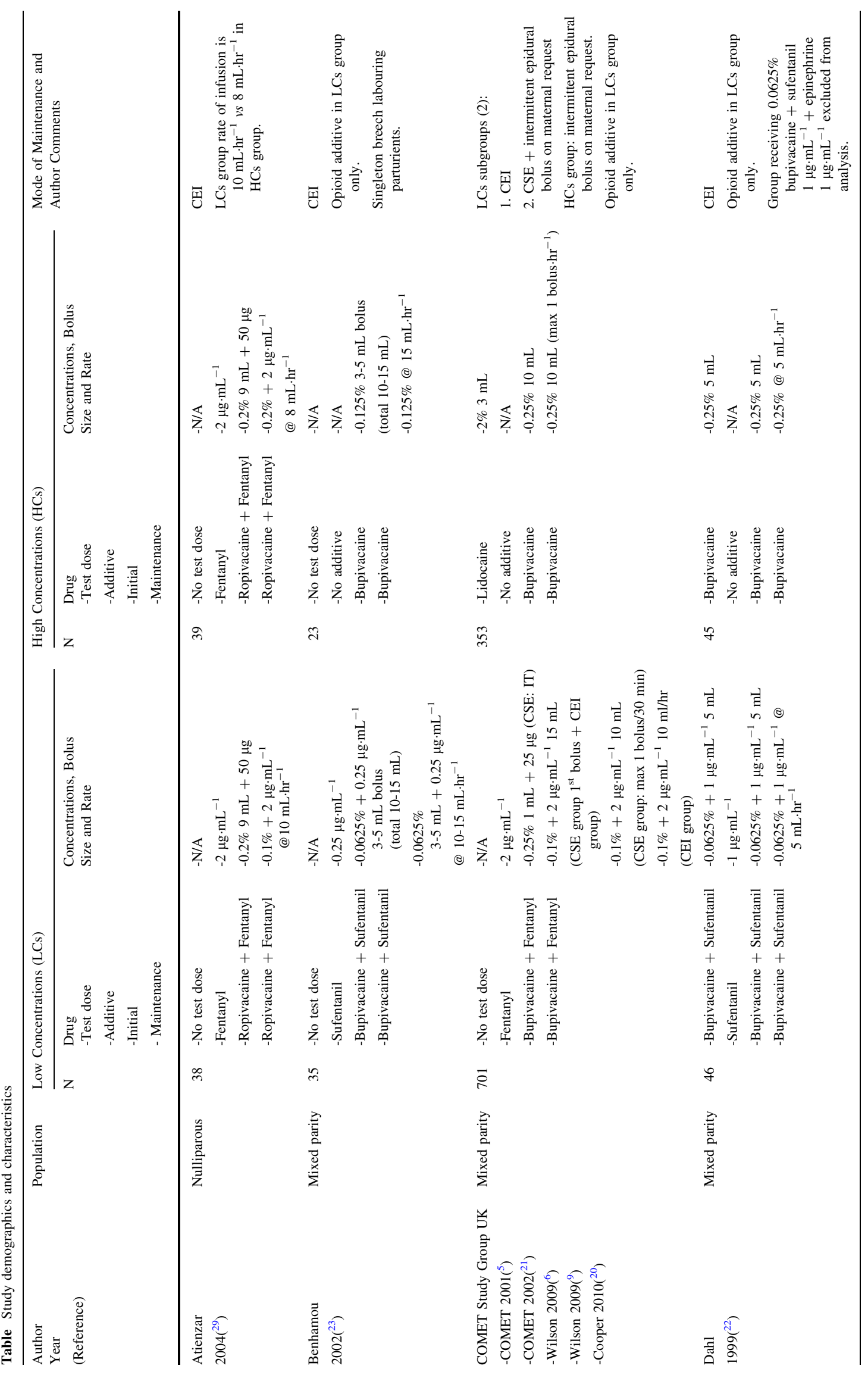




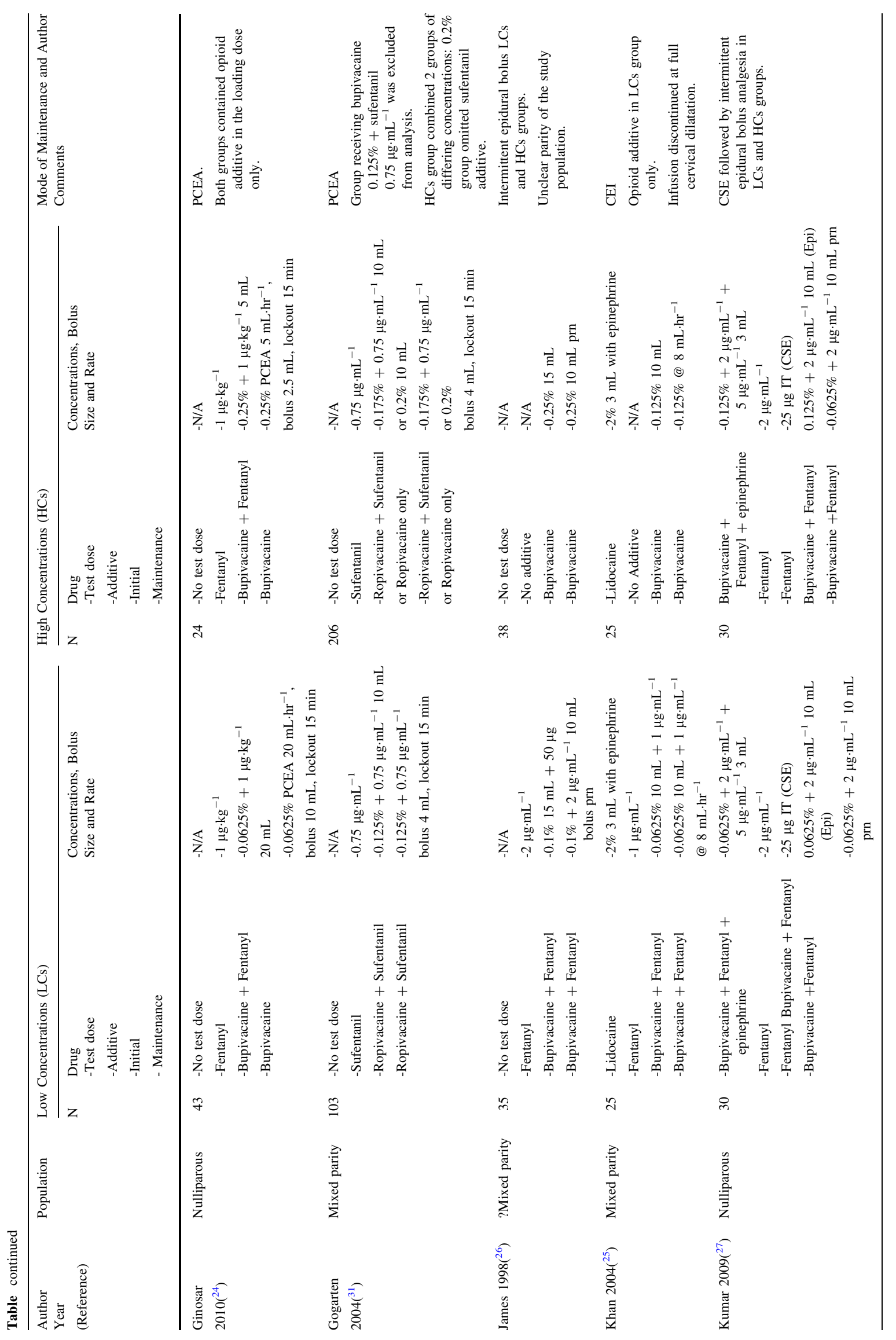




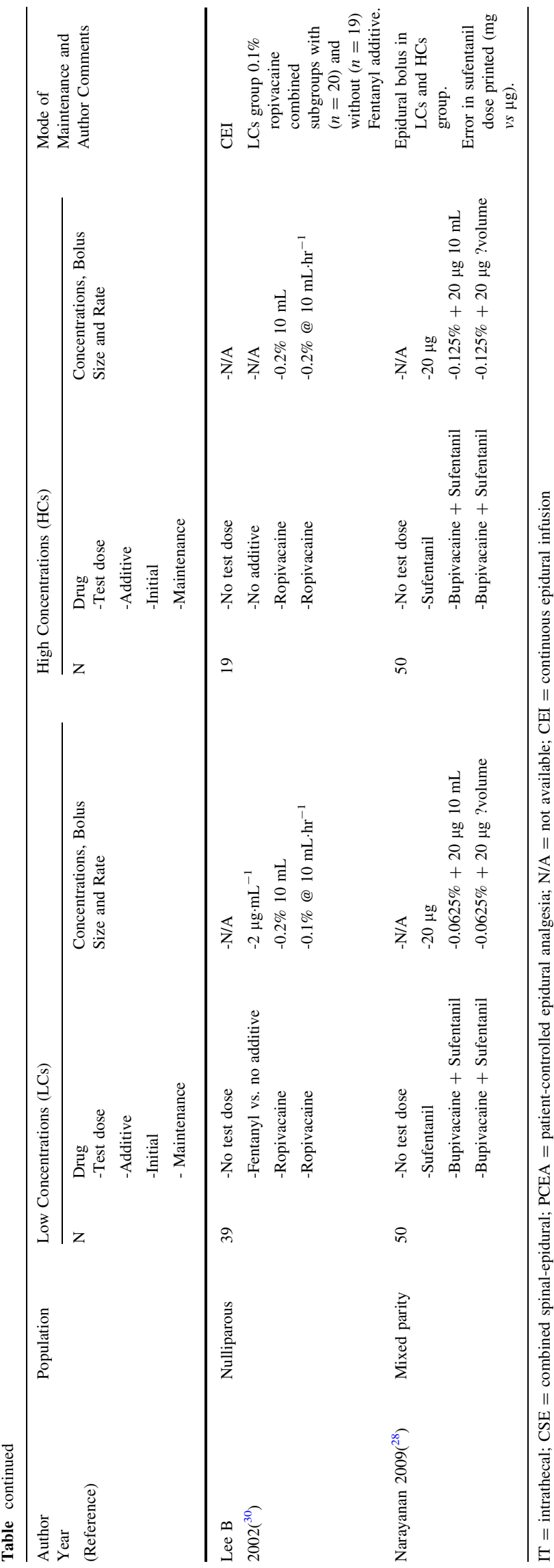

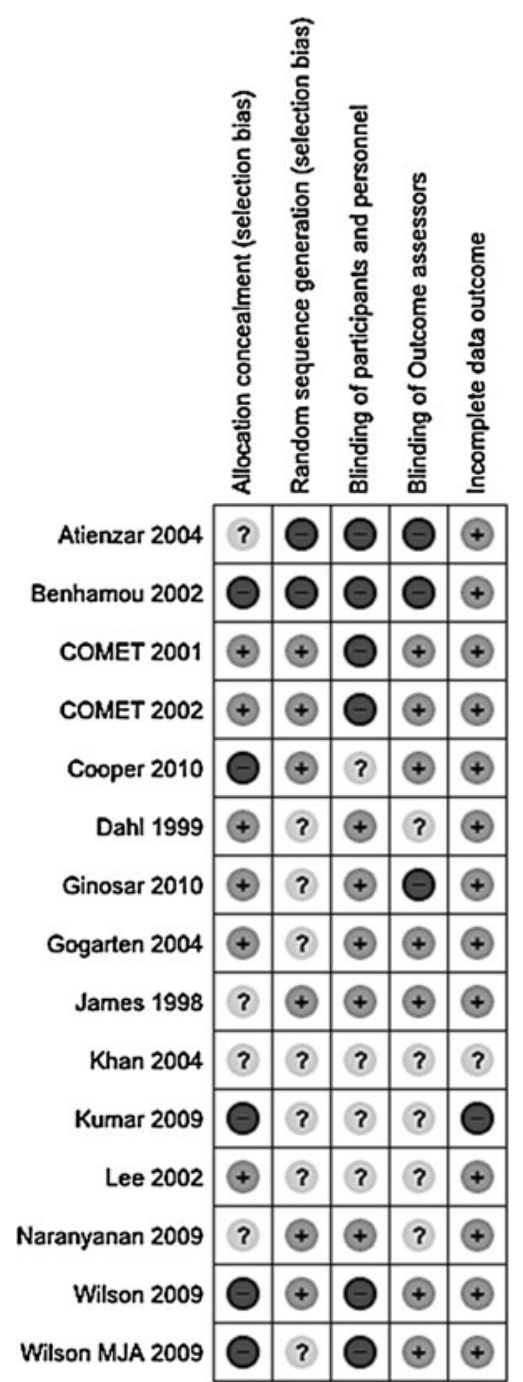

Fig. 2 Risk of bias

$-18.78 ; P<0.001$ ), while there were no differences in the number of patients requiring clinician top-ups (OR 1.08; $95 \%$ CI 0.83 to $1.39 ; P=0.58$ ). The incidence of no motor block (Bromage score $=0$ ) was higher in the LCs group (OR 3.90; 95\% CI 1.59 to $9.55 ; P=0.003$ ), and the ability to ambulate favoured the LCs group (OR 2.80; 95\% CI 1.10 to $7.14 ; P=0.03)$. There was a trend towards more pruritus in the LCs group (OR 3.36; 95\% CI 1.00 to 11.31; $P=0.05)$. Urinary retention was lower in the LCs group (OR $0.42 ; 95 \%$ CI 0.23 to $0.73 ; P=0.002$ ); however, the risk difference did not differ (RD $-0.13 ; 95 \% \mathrm{CI}-0.28$ to $0.02 ; P=0.09)$.

Fetal outcomes

Neonatal outcomes are summarized in Fig. 7. The odds of an Apgar $<7$ at one minute were greater in those receiving LC epidurals (Apgar at one minute OR 1.53; 95\% CI .07 to $2.21 ; P=0.02$ ). The Apgar $>7$ at five minutes (OR 2.67; 


\begin{tabular}{|c|c|c|c|c|c|c|c|c|c|}
\hline Study or Subgroup & \multicolumn{2}{|c|}{ Low Concentration } & \multicolumn{2}{|c|}{ High Concentration } & Weight & $\begin{array}{c}\text { Odds Ratio } \\
\text { M-H, Random, } 95 \% \mathrm{Cl}\end{array}$ & \multicolumn{2}{|c|}{$\begin{array}{c}\text { Odds Ratio } \\
\text { M-H, Random, } 95 \% \mathrm{Cl}\end{array}$} & \\
\hline Atienzar 2004 & 19 & 38 & 20 & 39 & $5.8 \%$ & $0.95[0.39,2.32]$ & $\longrightarrow$ & 5 & \\
\hline Benhamou 2002 & 21 & 35 & 16 & 23 & $3.7 \%$ & $0.66[0.21,2.00]$ & & & \\
\hline COMET 2001 & 200 & 701 & 131 & 353 & $62.8 \%$ & $0.68[0.52,0.89]$ & & & \\
\hline Dahl 1999 & 4 & 46 & 7 & 45 & $2.7 \%$ & $0.52[0.14,1.91]$ & & - & \\
\hline Ginosar 2010 & 12 & 43 & 8 & 24 & $4.0 \%$ & $0.77[0.26,2.28]$ & & & \\
\hline Gogarten 2004 & 22 & 103 & 39 & 206 & $13.4 \%$ & $1.16[0.65,2.09]$ & & & \\
\hline James 1998 & 2 & 35 & 9 & 38 & $1.8 \%$ & $0.20[0.04,0.98]$ & & & \\
\hline Khan 2004 & 0 & 25 & 2 & 25 & $0.5 \%$ & $0.18[0.01,4.04]$ & $\longleftarrow$ & & \\
\hline Kumar 2009 & 1 & 30 & 3 & 30 & $0.9 \%$ & $0.31[0.03,3.17]$ & & & \\
\hline Lee 2002 & 10 & 39 & 8 & 19 & $3.4 \%$ & $0.47[0.15,1.51]$ & & - & \\
\hline Naranyanan 2009 & 1 & 50 & 6 & 50 & $1.0 \%$ & $0.15[0.02,1.29]$ & & & \\
\hline Total $(95 \% \mathrm{CI})$ & & 1145 & & 852 & $100.0 \%$ & $0.70[0.56,0.86]$ & $\boldsymbol{\gamma}$ & & \\
\hline Total events & 292 & & 249 & & & & & & \\
\hline \multicolumn{7}{|c|}{$\begin{array}{l}\text { Heterogeneity: } \text { Tau }^{2}=0.00 ; \mathrm{Chi}^{2}=9.67, \mathrm{df}=10(P=0.47) ; \mathrm{I}^{2}=0 \% \\
\text { Test for overall effect: } Z=3.32(P=0.0009)\end{array}$} & $0.01 \quad 0.1$ & 10 & 100 \\
\hline
\end{tabular}

Fig. 3 Forest plot for the incidence of the primary outcome of assisted vaginal delivery (AVD)

(a) $C D$

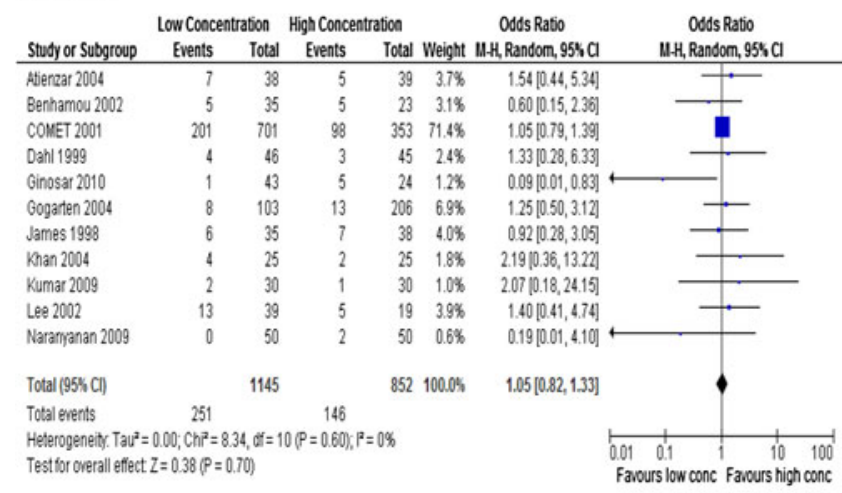

\section{(c) Duration of $1^{\text {st }}$ stage}

\begin{tabular}{|c|c|c|c|c|c|c|c|c|c|}
\hline \multirow[b]{2}{*}{ Studjor Subgroup } & \multicolumn{3}{|c|}{ Low Concentration } & \multicolumn{3}{|c|}{ Hagh Concentrafoon } & \multirow{2}{*}{$\begin{array}{l}\text { Hean OHflerence } \\
\text { N,Random,95s,Cl }\end{array}$} & \multirow{2}{*}{\multicolumn{2}{|c|}{$\begin{array}{l}\text { Ulean OHflerence } \\
\text { N, Random,95s:Cl }\end{array}$}} \\
\hline & Mlean & SD & Total & Hean & SO 1 & Total Weight & & & \\
\hline Benhamou 2002 & 355 & 149 & 35 & 334 & 153 & $235.6 \%$ & $21.00[58606,100.60]$ & & \\
\hline COMET 2001 & 528 & 283 & 701 & 514 & 274 & $35319.6 \%$ & $1400[-221.4,49,44]$ & & \\
\hline Ginosar 2010 & 330 & 36 & 43 & 355 & 38 & $2435.4 \%$ & $.25 .00[-4363,-637]$ & $-\Vdash$ & \\
\hline Gogaten 2004 & 193 & 282 & 103 & 192 & 151 & $2009.8 \%$ & $1.00[-57.23,59223]$ & & \\
\hline James 1998 & 395 & 56 & 35 & 430 & 61 & $3826.6 \%$ & $.3500[-61.84,-810]$ & $\rightarrow$ & \\
\hline Lee 2002 & 500 & 171 & 39 & 563 & 207 & $193.2 \%$. & $83.000-190.44,24.47]^{4}$ & & \\
\hline Total $\mid 55 \%$ Cl) & & & 956 & & & $6631000 \%$ & $.16 .83[36.81,3.16]$ & & \\
\hline 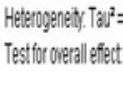 & $z=3.48 ;$ & $\begin{array}{l}h^{2}=7.8 \\
0=0.10\end{array}$ & $5, \mathrm{df}=5$ & $P=0.18$ & 6) $P=360 x$ & & & $\begin{array}{ll}00 & 500 \\
\text { fanours low conce }\end{array}$ & Farours \\
\hline
\end{tabular}

(b) SVD

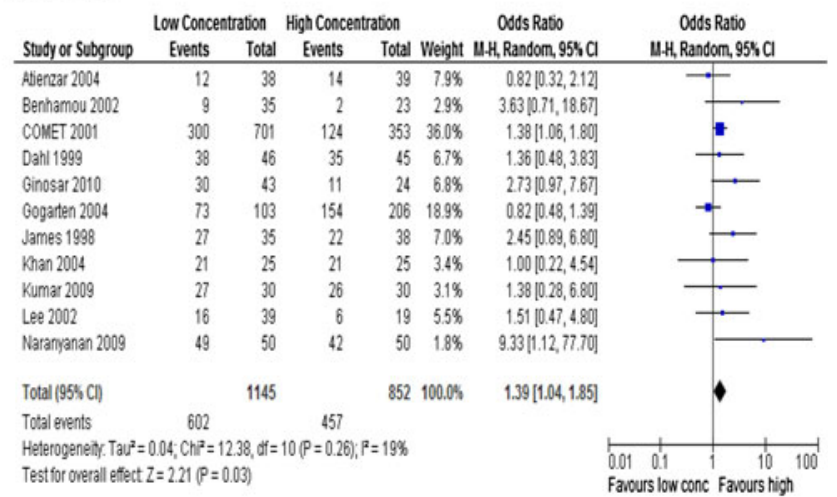

\section{(d) Duration of $2^{\text {nd }}$ stage}

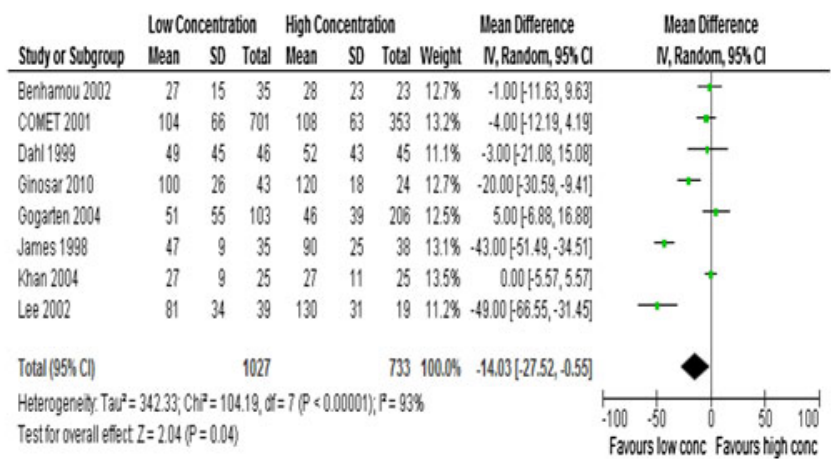

Fig. 4 Forest plots for obstetric outcomes of the incidence of A) Cesarean delivery (CD), B) spontaneous vaginal delivery (SVD), C) duration of first and D) second stages of labour (min)

95\% CI 0.84 to $8.47 ; P=0.09)$ and other neonatal outcomes did not differ between groups (Fig. 7).

\section{Discussion}

This meta-analysis evaluating 11 studies provides strong evidence to support the use of LCs of bupivacaine $(\leq 0.1 \%)$ or ropivacaine $(\leq 0.17 \%)$ to bring about a significant reduction in the rate of AVD. By using LCs of local anesthetic solution for epidural analgesia, 14 patients would need to be treated to prevent one additional AVD. The higher AVD rate associated with HCs of local anesthetics may be attributed to the increase in motor nerve blockade that subsequently impairs the Ferguson-Harris reflex initiating the urge to bear down. ${ }^{10}$ Our findings showing the use of 


\section{(a) Maternal pain score}

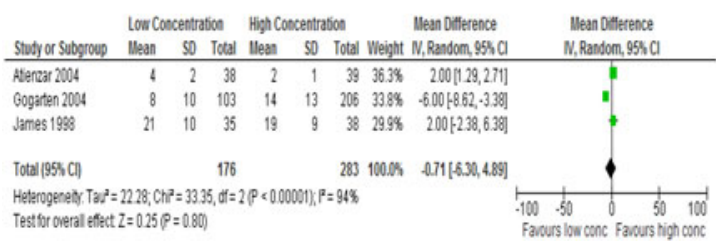

(c) Requirement for clinician top-ups

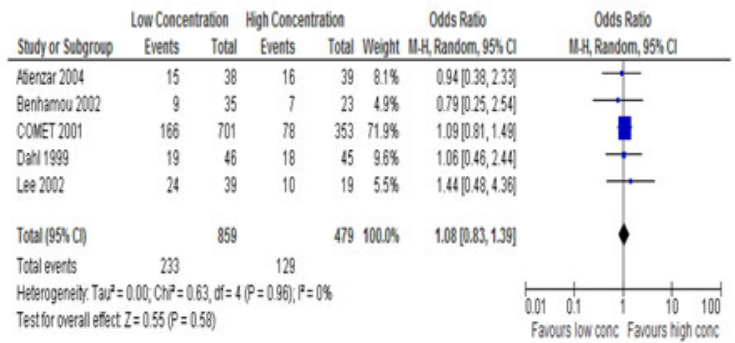

(e) Bromage score $>0$

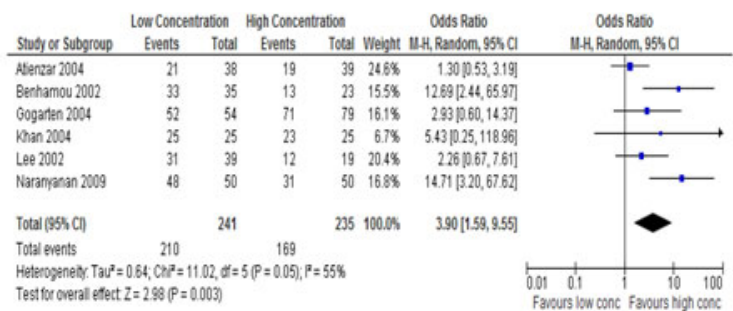

Fig. 5 Forest plots for maternal outcomes of A) pain score (visual or verbal analogue scale [VAS] 0-100 at 3 hours following neuraxial blockade placement), B) total dose of LA (mg), C) requirement of

significantly decreased dosages of local anesthetic and less motor blockade in the LCs group are consistent with this explanation.

Results of the 2001 COMET study showed a lower incidence of AVD with a $0.1 \%$ bupivacaine solution than with a $0.25 \%$ concentrations. ${ }^{5}$ Nevertheless, results from this study alone should be interpreted with caution due to numerous confounding factors, such as different methods of initiating analgesia (CSE vs epidural technique), initial doses, maintenance techniques (continuous infusion or intermittent bolus), drug concentrations, and group size. The three groups of patients in this study received different epidural induction and maintenance techniques. One group received an initial spinal dose of bupivacaine through a CSE technique followed by intermittent boluses on maternal request. Another group received an initial epidural dose followed by continuous infusion of the same local anesthetic mixture containing $0.1 \%$ bupivacaine and fentanyl $2 \mu \mathrm{g} \cdot \mathrm{mL}^{-1}$, and the final group received a higher dose of epidural mixture $(0.25 \%$ bupivacaine $10 \mathrm{~mL}$ with no opioid) followed by intermittent $10 \mathrm{~mL}$ boluses of $0.25 \%$ bupivacaine as per maternal request. In this meta- (b) Total dose of local anesthetic

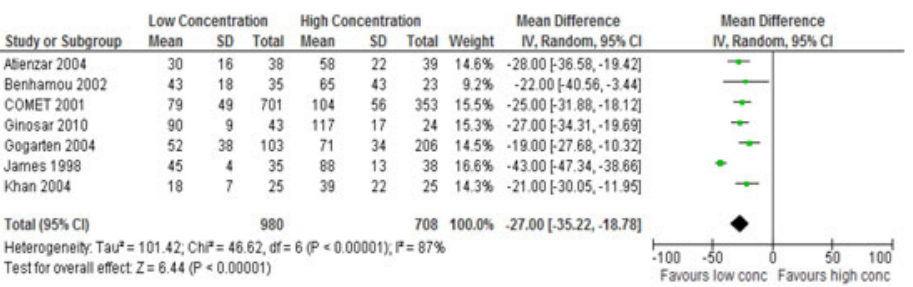

(d) Maternal $1^{\text {st }}$ stage satisfaction

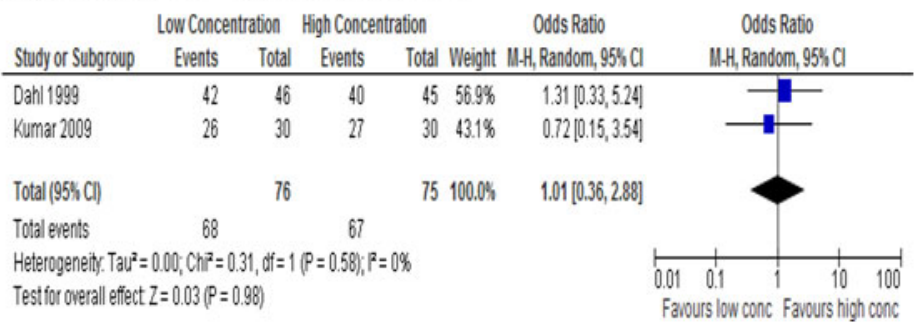

(f) Inability to ambulate

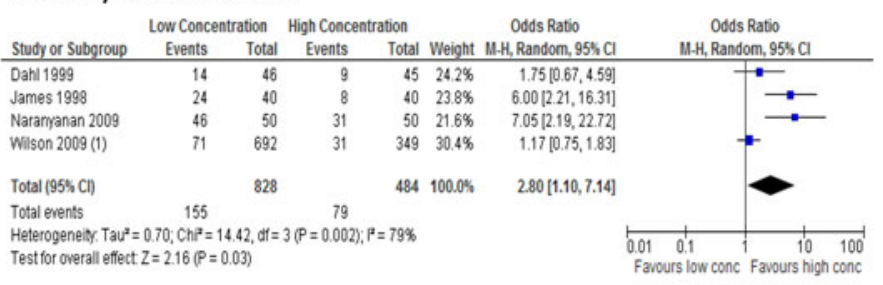

(1) Couet Study Group UK

clinician top-ups, D) maternal first stage satisfaction $(\mathrm{n} / \mathrm{N})$, E) Bromage score $>0$, and F) inability to ambulate

analysis, we attempted to minimize the heterogeneity of studies by excluding those which utilized HCs of local anesthetic for test dose or initiation or maintenance of analgesia in the intention-to-treat analysis of data.

Differences in obstetric and anesthetic management may impact the rate of $\mathrm{AVD}^{4}$ There was considerable variability in the rates of AVD in the studies included in this meta-analysis, showing that local obstetric practice most likely influences AVD to a greater extent than the anesthetic technique alone. Nevertheless, despite these variations in "baseline" rates of AVD between the different centres performing the studies, the overall rate of AVD is reduced with LCs of local anesthetics. The magnitude of the change in the rate of AVD appears to be consistent as shown by the minimal statistical heterogeneity among the studies $\left(\mathrm{I}^{2}=0 \%\right)$. The similar rates of Cesarean delivery between the LC and $\mathrm{HC}$ groups suggest that the increased rate of AVD associated with regional anesthesia does not appear to be associated with an increase in Cesarean delivery. This finding is consistent with evidence that epidurals do not increase the rate of Cesarean delivery. ${ }^{1,33}$ Prolongation of labour has been 


\section{(a) Nausea and vomiting}

(b) Maternal hypotension

(c) Pruritus

\section{(d) Urinary retention}

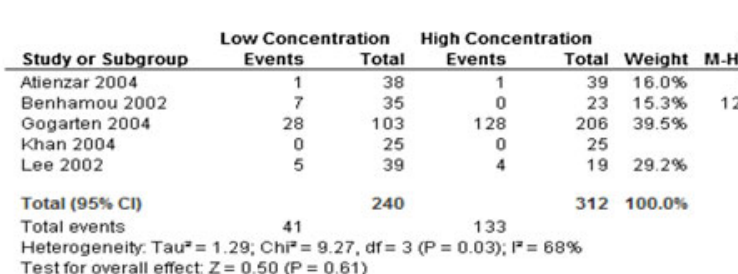

Heterogeneity. Tau $=1.29 ; \mathrm{Chi}^{2}=9.27, \mathrm{dr}=3$
Test for overall effect: $\mathrm{Z}=0.50(\mathrm{P}=0.61)$

\begin{tabular}{|c|c|c|c|c|c|}
\hline \multirow[b]{2}{*}{ Study or Subgroup } & \multicolumn{2}{|c|}{ Low Concentration } & \multicolumn{2}{|c|}{ High Concentration } & \multirow[b]{2}{*}{ Weight } \\
\hline & Events & Total & Events & Total & \\
\hline Atienzar 2004 & 6 & 38 & 1 & 39 & $20.4 \%$ \\
\hline Benhamou 2002 & 2 & 35 & 2 & 23 & $21.6 \%$ \\
\hline Dahl 1999 & 0 & 46 & 3 & 45 & $14.3 \%$ \\
\hline Gogarten 2004 & 5 & 103 & 0 & 206 & $14.8 \%$ \\
\hline Lee 2002 & 10 & 39 & 4 & 19 & $29.0 \%$ \\
\hline Total $(95 \% \mathrm{Cl})$ & & 261 & & 332 & $100.0 \%$ \\
\hline Total events & 23 & & 10 & & \\
\hline
\end{tabular}

Heterogeneity: $\operatorname{Tau}^{2}=1.38 ; \mathrm{Chi}^{2}=8.75, \mathrm{df}=4(P=0.07) ; \mathrm{I}^{2}=54 \%$

Test for overall effect: $Z=0.76(P=0.45)$

\begin{tabular}{|c|c|c|c|c|c|}
\hline \multirow[b]{2}{*}{ Study or Subgroup } & \multicolumn{2}{|c|}{ Low Concentration } & \multicolumn{2}{|c|}{ High Concentration } & \multirow[b]{2}{*}{ Weigh } \\
\hline & Events & Total & Events & Total & \\
\hline Atienzar 2004 & 2 & 38 & 1 & 39 & $16.4 \%$ \\
\hline Benhamou 2002 & 10 & 35 & 0 & 23 & $13.0 \%$ \\
\hline Dahl 1999 & 9 & 46 & 0 & 45 & $13.1 \%$ \\
\hline Gogarten 2004 & 48 & 103 & 76 & 206 & $45.8 \%$ \\
\hline Khan 2004 & 0 & 25 & 0 & 25 & \\
\hline Lee 2002 & 2 & 39 & 0 & 19 & $11.8 \%$ \\
\hline Total $(95 \% \mathrm{Cl})$ & & 286 & & 357 & $100.0 \%$ \\
\hline Total events & 71 & & 77 & & \\
\hline
\end{tabular}

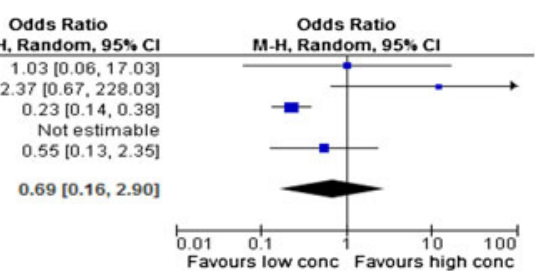

Odds Ratio Odds Ratio

H. Random, $95 \% \mathrm{Cl}$ 7.13 [0.81, 62.32] M-H, Random, 95\% Cl

$0.64[0.08,4.87]$

$0.13[0.01,2.60]$

$23.06[1.26,421.21]$
$1.29[0.35,4.82]$

$1.74[0.42,7.23]$

$1.7410 .42,7.231$

\section{เ}

$\begin{array}{ll}\text { Odds Ratio } & \text { Odds Ratio } \\ \text { Random, 95\% Cl } & \text { M-H, Random, 95\% }\end{array}$

H, Random, 95\% Cl M. H, Random, 95\% Cl

$2.11[0.18,24.30]$
$19.35[1.07,348.87]$

$23.05[1.30,409.24]$

$1.49[0.92,2.41]$

Not estimable
$2.60[0.12,56.87]$

$3.36[1.00,11.31]$

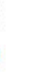
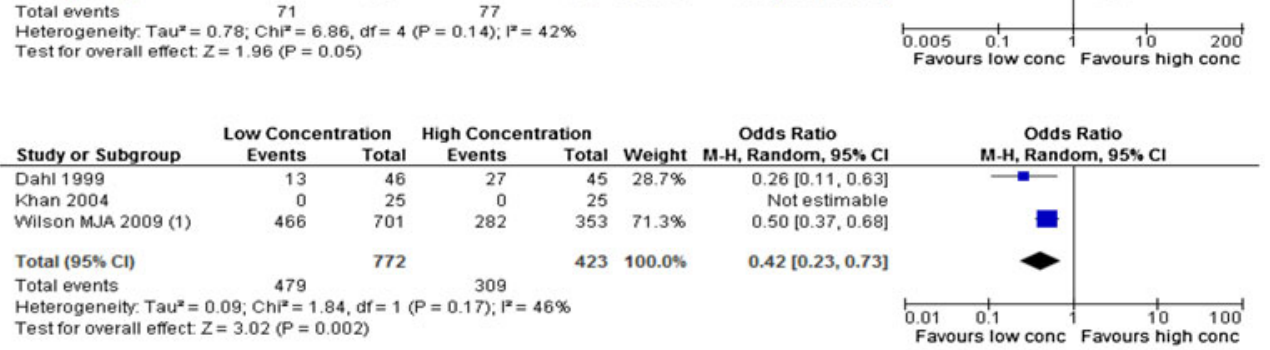

(1) COMET Study Group UK

Fig. 6 Forest plots for maternal side effects of A) nausea and vomiting, B) maternal hypotension, C) pruritus, and D) urinary retention

associated with epidural labour analgesia. ${ }^{1,34,35}$ The prolonged second stage of labour we observed suggests that this phenomenon may be an effect of the concentration of local anesthetic.

The aim of this study was to show that HCs of local anesthetic are associated with increased AVD. The metaanalysis was designed to show the impact of concentrations of local anesthetic on AVD and not to determine a specific cut-off concentration of local anesthetic beyond which AVD increases. Future dose-finding studies are needed to determine the optimal concentration of local anesthetic to minimize AVD. Additionally, AVD was the primary outcome of interest in designing this study, and the other clinical end points in this meta-analysis should be considered secondary outcome measures.

There were no clinically significant differences in pain scores between the LC and HC groups. For pain scores, we chose a three-hour time point after commencing epidural analgesia. In our view, this interval would most likely reflect the time when analgesia would be achieved by a method to maintain local anesthetic rather than by residual effects of the initial method or agents used to establish the neuraxial blockade. Despite a lower total dose of local anesthetic utilized in the LCs group, there was no subsequent increase in the number of interventions required by the anesthesia care provider to treat labour pain in this group, and maternal satisfaction scores were similar between both groups. Opioid-related side effects, such as pruritus, nausea and vomiting, hypotension, and urinary retention, are well recognized after neuraxial labour analgesia. ${ }^{15}$ With the exceptions of a higher incidence of urinary retention in the HCs group $(P=0.002)$, we did not find significant differences in any of these side effects. The trend towards a decreased incidence in pruritus shown in the HCs group may be attributable to the absence of opioid in the HCs groups in two of the six studies. ${ }^{22,23}$ Since the opioid utilized varied among the studies (fentanyl, ${ }^{5,24-27,29,30}$ sufentanil), ${ }^{22,23,28,31}$ the incidence of pruritus caused by the epidural opioid, the opioid dose utilized, and the combination of opioid and type of local anesthetic utilized remain unclear from this metaanalysis.

We hypothesize that the odds of one-minute Apgar scores $>7$ favouring the HCs group in this meta-analysis may be due to the higher opioid doses utilized in the LCs 
(a) Apgar score $<7$ at $1 \mathrm{~min}$

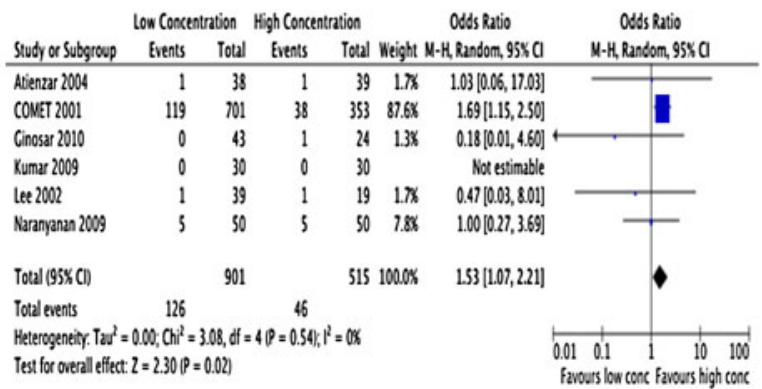

(c) FHR abnormality

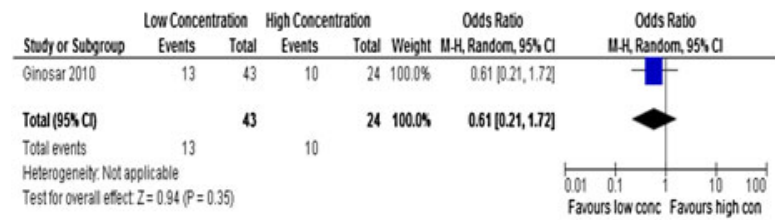

(b) Apgar score $<7$ at 5 mins

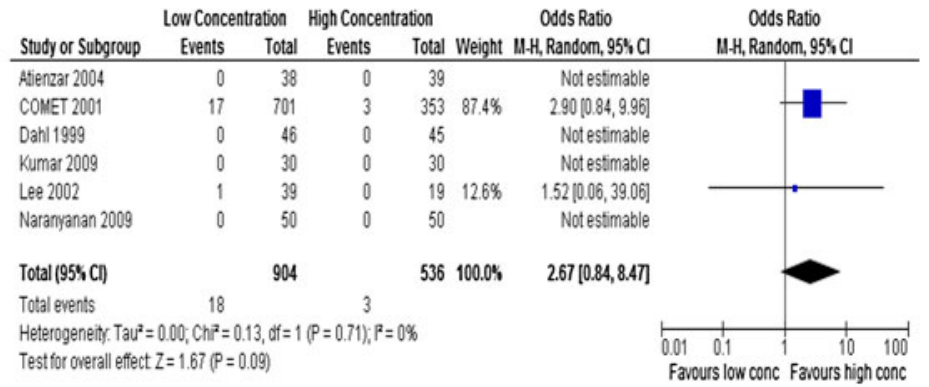

(e) Requirement for neonatal resuscitation

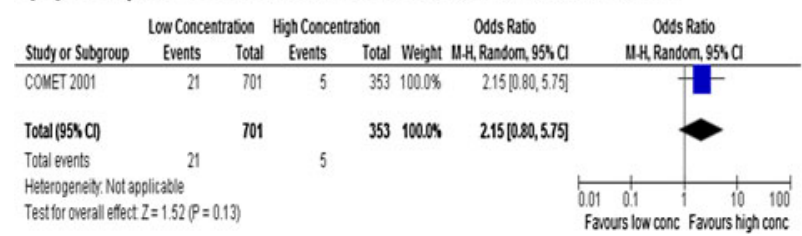

(d) Umbilical artery $\mathrm{pH}$

\begin{tabular}{|c|c|c|c|c|c|c|c|c|c|}
\hline \multirow[b]{2}{*}{ Study or Subgroup } & \multicolumn{3}{|c|}{ Low Concentration } & \multicolumn{3}{|c|}{ High Concentration } & & \multirow{2}{*}{$\begin{array}{l}\text { Mean Difference } \\
\text { N, Random, } 95 \mathrm{~s} \mathrm{Cl}\end{array}$} & \multirow{2}{*}{$\begin{array}{c}\text { Mean Difference } \\
\mathrm{N}, \text { Random, } 95 \mathrm{~h} \mathrm{Cl}\end{array}$} \\
\hline & Mean & SD & Total & Mean & SD & Total & Weight & & \\
\hline Benhamou 2002 & 7.29 & 0.03 & 35 & 7.29 & 0.06 & 23 & $100.0 \%$ & $0.00[-0.03,0.03]$ & \\
\hline Total (95\% CD) & & & 35 & & & 23 & $100.0 \%$ & $0.00[-0.03,0.03]$ & \\
\hline $\begin{array}{l}\text { Heterogeneidy, Not a } \\
\text { Test for overall effect }\end{array}$ & olicable & $P=1.00$ & & & & & & & 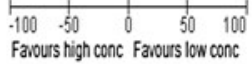 \\
\hline
\end{tabular}

Fig. 7 Forest plots for neonatal outcomes of A) Odds of Apgar score $<7$ at one minute and B) at five minutes, C) fetal heart rate (FHR) abnormality, D) umbilical artery $\mathrm{pH}$, and $\mathrm{E}$ ) requirement for neonatal resuscitation

group. The opioids associated with LCs of local anesthetic solutions may have crossed the placenta and increased early respiratory depression and neonatal sedation in this group. Even so, the Apgar scores must be interpreted with caution since no studies had neonatal outcomes as their primary outcome measure. Most studies did not measure or report fetal outcomes, and all studies were underpowered to find differences between groups. Unlike five-minute Apgar scores, low one-minute scores are not associated with poor developmental outcome. ${ }^{36}$ The conclusion from the COMET trial that "possible adverse effects to the neonate should be weighed against the advantages gained by avoidance of an instrumental delivery" with LCs of epidural solutions should still be appreciated.

There are a number of potential limitations of this metaanalysis. While the majority of studies identified favoured LCs, it should be appreciated that the COMET study contributed $63 \%$ of the weight of the meta-analysis and therefore makes a substantial contribution to the overall OR. Nevertheless, there was consistency among the included studies when reporting our primary outcome of AVD and other obstetric outcomes (Cesarean delivery, duration of labour). Despite the studies utilizing different techniques and protocols for initiation and maintenance of labour analgesia and various opioid regimens, this metaanalysis shows minimal heterogeneity for the primary outcome. Other limitations include searching only one trial registry (clinicaltrials.gov), variations in methods of grading secondary outcomes, and not all studies reported every outcome. Varying definitions (e.g., pruritus, nausea), measurement intervals and scoring systems (for maternal satisfaction and fetal well-being) made it challenging to determine whether true reproducible differences existed between groups for secondary outcome measurements. We did not control for the timing of epidural placement; however, there appears to be no difference in incidence of AVD between early and late epidural in labour. ${ }^{37}$

In conclusion, LCs $(\leq 0.1 \%$ bupivacaine or equivalent ropivacaine dose) of labour epidural solutions improve obstetric outcomes (decreased AVD, shorter duration of second stage of labour) and reduce maternal side effects (less motor blockade, better ambulation, and decreased urinary retention) without compromising analgesia. Adverse neonatal effects (lower one-minute Apgar scores) with questionable clinical significance should be weighed against the clear maternal advantages gained. Low concentrations of local anesthetic epidural solutions appear preferable to HCs to optimize obstetric outcome, and on 
balance, we would recommend the use of LCs for epidural analgesia for the provision of labour analgesia.

Acknowledgment Support for this study was provided solely from institutional and or departmental sources.

Conflicts of interest No external funding and no competing interests declared.

\section{Appendix 1: PubMed Search criteria utilized in the study}

1. ("ropivacaine"[Supplementary Concept] OR "Bupivacaine"[Mesh] OR bupivacaine[tiab] OR ropivacaine[tiab])

2. ("Obstetric Labor Complications" [Mesh] OR "Labor, Obstetric"[Mesh] OR "Delivery, Obstetric"[Mesh] OR caesarean[ti] OR birth[ti] OR labour[ti] OR labor[ti])

3. (((random*[tiab] OR placebo*[tiab] OR controls[tiab] OR control[tiab] OR controlled[tiab] OR trial[ti] OR "double blind" [tiab] OR blinded[tiab] OR "single blind"[tiab] OR "clinical trial"[tiab] OR "clinical trials"[tiab] OR ((singl*[tiab] OR doubl*[tiab] OR trebl*[tiab] OR tripl*[tiab]) AND (mask*[tiab] OR blind*[tiab])) OR "latin square"[tiab] OR prospectiv*[tiab] OR volunteer*[tiab]) NOT medline[sb]) OR ((randomized controlled trial[pt] OR controlled clinical trial[pt] OR random*[tiab] OR placebo[tiab] OR "clinical trials as topic"[mesh] OR trial[ti])))

\section{Appendix 2: Review Protocol}

High $v s$ Low concentration of local anesthetic for labour $1^{\text {st }}$ Author _ _ _ _ Year of Publication Extracted by

Methodology

\begin{tabular}{lll}
\hline Item & Low & High \\
& Concentration & Concentration \\
\hline
\end{tabular}

Number of patients $(\mathrm{N})$

Blinded allocation $\mathrm{Y} / \mathrm{N}$

Allocation Concealment

Random Sequence Generation

Blinding of participants/ personnel

Blinding of outcome assessors

Incomplete data outcome

Test dose

\begin{tabular}{lll}
\hline Item & Low & High \\
& Concentration & Concentration \\
\hline
\end{tabular}

Additive

Initial dose

Maintenance

Population (nullip/mixed)

SVD $\mathrm{n} / \mathrm{N}$

Assisted vaginal $\mathrm{n} / \mathrm{N}$

Cesarean $\mathrm{n} / \mathrm{N}$

Apgar $<7 \mathrm{n} / \mathrm{N}$ one minute

Apgar $<7 \mathrm{n} / \mathrm{N}$ five minutes

Umbilical $\mathrm{pH}<7.2 \mathrm{n} / \mathrm{N}$

Umbilical pH Mean (SD)

Need for neonatal rescus $n / \mathrm{N}$

Duration of $1^{\text {st }}$ stage min (SD)

Duration of $2^{\text {nd }}$ stage min (SD)

Clinician top-ups $\mathrm{n} / \mathrm{N}$ or additional meds requested

Total dose of local anesthetic mean (SD)

Pain score

Bromage $=0 \mathrm{n} / \mathrm{N}$

Ambulation $\mathrm{n} / \mathrm{N}$

Maternal hypotension $\mathrm{n} / \mathrm{N}$

FHR abnormalities $\mathrm{n} / \mathrm{N}$

Itch $\mathrm{n} / \mathrm{N}(\mathrm{mod} / \mathrm{severe})$

Urinary retention

Maternal satisfaction $1^{\text {st }}$ stage $\mathrm{n} / \mathrm{N}$

Maternal satisfaction $2^{\text {nd }}$ stage $n / N$

Nausea /vomiting n/N

Estimated median duration of analgesia ( $\mathrm{min})$

\section{Comments:}

\section{Appendix 3: Excluded Studies}

Bupivacaine Studies:

1. Dennison $1990\left({ }^{63}\right)$-letter.

2. Dresner $1999\left({ }^{64}\right)$-epidural vs spinal study.

3. Elliot $1991\left({ }^{65}\right)-0.125 \%$ vs $0.25 \%$ bupivacaine.

4. Lyons $2007\left({ }^{66}\right)-0.125 \%$ vs $0.25 \%$ bupivacaine.

5. Marcoux $1987\left({ }^{67}\right)-0.375 \%$ vs $0.5 \%$ bupivacaine.

6. Olofsson $1997\left({ }^{50}\right)-0.125 \%$ vs $0.25 \%$ bupivacaine.

7. Olofsson $1998\left({ }^{38}\right)-0.125 \%$ vs $0.25 \%$ bupivacaine.

8. Stainthorpe $1978\left({ }^{51}\right)-0.125 \%$ vs $0.375 \%$ vs $0.25 \%$ bupivacaine.

9. Tan $1994\left({ }^{52}\right)-0.25 \%$ vs $0.125 \%$ bupivacaine.

10. Thorburn $1981\left({ }^{53}\right)-0.25 \%$ vs $0.5 \%$ bupivacaine. 
11. Handley $1992\left({ }^{54}\right)-0.125 \%$ vs $0.1875 \%$ vs $0.25 \%$ bupivacaine.

12. Moir $1975\left({ }^{55}\right)-0.5 \%$ bupivacaine with epinephrine $v s$ $0.5 \%$ bupivacaine vs $2 \%$ lidocaine vs $2 \%$ lidocaine with epinephrine.

13. Harms $1999\left({ }^{56}\right)-0.0625 \%$ vs $0.125 \%$ vs $0.25 \%$ bupivacaine. Comparison of initial concentration used to establish block. No infusion was administered.

14. Paech $1993\left({ }^{57}\right)-0.0625 \%$ vs $0.125 \%$ vs $0.25 \%$ bupivacaine. Low-dose contained epinephrine.

15. Russell $1995\left({ }^{58}\right)-0.0625 \%$ vs $0.125 \%$ bupivacaine. Excluded since same cohort of patients used as 1996 study.(45)

16. Scrutton $1998\left({ }^{59}\right)$-Initial concentration used to establish block varied (bupivacaine $0.0625 \%$ vs $0.125 \%$ vs $0.25 \%$ ); however, infusions following initial dose were the same $(0.0625 \%$ bupivacaine).

17. Cohen $2000\left({ }^{60}\right)$-Initial dose with bupivacaine $0.0625 \%$ vs $0.125 \%$ bupivacaine (with sufentanil). Same infusion concentration and dose in both groups.

18. Christiaens $1998\left({ }^{61}\right) \quad-0.5 \%$ vs $\quad 0.2 \%$ vs $0.1 \%$ bupivacaine. No infusion, therefore excluded. Study looked at effects of initial bolus concentration only.

19. Brockway $1990\left({ }^{74}\right)-0.08 \%$ vs $0.0625 \%$ bupivacaine for continuous epidural analgesia in labour. Both concentrations $<0.1 \%$ bupivacaine.

20. Nageotte $1997\left({ }^{75}\right)$-One group received bolus and the other group received infusion. Combined spinalepidural (CSE) vs continuous infusion. Study did not look at the effects of different concentrations. They divided groups by epidural $v s$ CSE and whether or not they were encouraged to ambulate.

21. Wang 2010 $\left({ }^{68}\right)$-Comparison between bupivacaine, ropivacaine, and levo-bupivacaine. No data recorded comparing different concentrations within groups.

22. Sanchez-Pereles $1999\left({ }^{62}\right)-0.0625 \%$ bupivacaine and 1:600,000 epinephrine vs $0.125 \%$ bupivacaine and 1:800,000 epinephrine. Excluded due to epinephrine.

23. Castro 2000 $\left({ }^{69}\right)$-Comparison between group 1 ( $0.0625 \%$ bupivacaine with $1: 800,000$ epinephrine with $20 \mu \mathrm{g}$ fentanyl at $10 \mathrm{~mL} \cdot \mathrm{hr}^{-1}$ ) and group 2 $(0.125 \%$ bupivacaine with $1: 400,000$ epinephrine with $20 \mu \mathrm{g}$ fentanyl at $10 \mathrm{~mL} \cdot \mathrm{hr}^{-1}$ ). Excluded due to epinephrine.

24. Shrestha $2007\left({ }^{32}\right)$-Article could not be accessed.

25. Chestnut $1988\left({ }^{49}\right)$ - Epinephrine utilized in test dose, test dose utilized $0.5 \%$ bupivacaine in the low concentration group, and initial dose utilized was also $>0.1 \%$ in the low concentration group.

26. Lowson $1995\left({ }^{48}\right)$ - Test dose and initial dose in low concentration group $>0.1 \%$ bupivacaine.

27. Beilin $2002\left({ }^{47}\right)$ - Initial dose $>0.1 \%$ bupivacaine in the low concentration group.
28. Noble $1991\left({ }^{46}\right)$ - Initial dose $>0.1 \%$ bupivacaine in the low concentration group.

29. Russell $1996\left({ }^{45}\right)$ - Initial dose $>0.1 \%$ bupivacaine in the low concentration group.

30. Ewen $1986\left({ }^{44}\right)$ - Initial dose $>0.1 \%$ bupivacaine in the low concentration group.

31. Ferrante $1995\left({ }^{43}\right)$ - Initial dose $>0.1 \%$ bupivacaine in the low concentration group.

32. Stoddart $1994\left({ }^{42}\right)$ - Initial dose $>0.1 \%$ bupivacaine in the low concentration group.

33. Rodriguez $1990\left({ }^{41}\right)$ - Initial dose $>0.1 \%$ bupivacaine in the low concentration group.

34. Li $1985\left({ }^{40}\right)$ - Initial dose $>0.1 \%$ bupivacaine in the low concentration group.

35. Hicks $1988\left({ }^{39}\right)$ - Initial dose $>0.1 \%$ bupivacaine in the low concentration group.

\section{Ropivacaine articles:}

1) Bernard $2003\left({ }^{70}\right)$-Ropivacaine 0.1 vs $0.2 \%$. Varied dose and volume between groups and in early and late labour, and no background infusion.

2) Sia $1999\left({ }^{71}\right)$ - Initial dose $>0.17 \%$ ropivacaine in the low concentration group.

3) Boselli $2003\left({ }^{72}\right)$-Ropivacaine 0.1 vs $0.15 \%$. Excluded based on concentrations.

4) Beilin $1999\left({ }^{73}\right)$-Ropivacaine $0.2 \%, 0.15 \%, 0.1 \%$. Patients given one extra intermittent bolus as required, no background infusion administered. Dose finding study.

\section{References}

1. Halpern SH, Leighton BL, Ohlsson A, Barrett JF, Rice A. Effect of epidural vs parenteral opioid analgesia on the progress of labor: a meta-analysis. JAMA 1998; 280: 2105-10.

2. Howell CJ. Epidural versus non-epidural analgesia for pain relief in labour. Cochrane Database Syst Rev 2000; 2: CD000331.

3. Howell CJ, Chalmers I. A review of prospectively controlled comparisons of epidural with non-epidural forms of pain relief during labour. Int J Obstet Anesth 1992; 1: 93-110.

4. Anim-Soтиah $M$, Smyth $R$, Howell $C$. Epidural versus nonepidural or no analgesia in labour. Cochrane Database Syst Rev 2005; 4: CD000331.

5. Comparative Obstetric Mobile Epidural Trial (COMET) Study Group UK. Effect of low-dose mobile versus traditional epidural techniques on mode of delivery: a randomised controlled trial. Lancet 2001; 358: 19-23.

6. Wilson MJ, MacArthur C, Cooper GM, Shennan A, COMET Study Group UK. Ambulation in labour and delivery mode: a randomised controlled trial of high-dose vs mobile epidural analgesia. Anaesthesia 2009; 64: 266-72. 
7. Szarvas S, Harmon D, Murphy D. Neuraxial opioid-induced pruritus: a review. J Clin Anesth 2003; 15: 234-9.

8. Simmons SW, Cyna AM, Dennis AT, Hughes D. Combined spinalepidural versus epidural analgesia in labour. Cochrane Database Syst Rev 2007; 3: CD003401.

9. Wilson MJ, Macarthur C. Shennan A; COMET Study Group $(U K)$. Urinary catheterization in labour with high-dose vs mobile epidural analgesia: a randomized controlled trial. $\mathrm{Br} \mathrm{J}$ Anaesth 2009; 102: 97-103.

10. Mardirosoff C, Dumont L, Boulvain M, Tramer MR. Fetal bradycardia due to intrathecal opioids for labour analgesia: a systematic review. BJOG 2002; 109: 274-81.

11. Lim Y, Ocampo CE, Supandji M, Teoh WH, Sia AT. A randomized controlled trial of three patient-controlled epidural analgesia regimens for labor. Anesth Analg 2008; 107: 1968-72.

12. Okutomi T, Saito M, Mochizuki J, Amano K, Hoka S. A doubleblind randomized controlled trial of patient-controlled epidural analgesia with or without a background infusion following initial spinal analgesia for labor pain. Int J Obstet Anesth 2009; 18 : 28-32.

13. Srivastava $U$, Gupta A, Saxena $S$, et al. Patient controlled epidural analgesia during labour: effect of addition of background infusion on quality of analgesia \& maternal satisfaction. Indian J Anaesth 2009; 53: 649-53.

14. Ferrante FM, Rosinia FA, Gordon C, Datta $S$. The role of continuous background infusions in patient-controlled epidural analgesia for labor and delivery. Anesth Analg 1994; 79: 80-4.

15. Loubert $C$, Hinova A, Fernando $R$. Update on modern neuraxial analgesia in labour: a review of the literature of the last 5 years. Anaesthesia 2011; 66: 191-212.

16. Polley LS, Columb MO, Naughton NN, Wagner DS, van de Ven $C J$. Relative analgesic potencies of ropivacaine and bupivacaine for epidural analgesia in labor: implications for therapeutic indexes. Anesthesiology 1999; 90: 944-50.

17. Capogna $G$, Celleno D, Fusco P, Lyons $G$, Columb M. Relative potencies of bupivacaine and ropivacaine for analgesia in labour. Br J Anaesth 1999; 82: 371-3.

18. Higgins JPT, Altman DG. Chapter 8: Assessing risk of bias in included studies. London: John Wiley \& Sons Ltd.; 2008 .

19. DerSimonian R, Laird N. Meta-analysis in clinical trials. Control Clin Trials 1986; 7: 177-88.

20. Cooper GM, MacArthur C, Wilson MJ, Moore PA. Shennan A; COMET Study Group UK. Satisfaction, control and pain relief: short- and long-term assessments in a randomised controlled trial of low-dose and traditional epidurals and a non-epidural comparison group. Int J Obstet Anesth 2010; 19: 31-7.

21. Wilson MJ, Cooper G, MacArthur C. Shennan A; Comparative Obstetric Mobile Epidural Trial (COMET) Study Group UK. Randomized controlled trial comparing traditional with two "mobile" epidural techniques: anesthetic and analgesic efficacy. Anesthesiology 2002; 97: 1567-75.

22. Dahl V, Hagen I, Koss KS, Nordentoft J, Raeder JC. Bupivacaine $2.5 \mathrm{mg} / \mathrm{ml}$ versus bupivacaine $0.625 \mathrm{mg} / \mathrm{ml}$ and sufentanil 1 microg/ml with or without epinephrine $1 \mathrm{microg} / \mathrm{ml}$ for epidural analgesia in labour. Int J Obstet Anesth 1999; 8: 155-60.

23. Benhamou D, Mercier FJ. Ben Ayed M, Auroy Y. Continuous epidural analgesia with bupivacaine $0.125 \%$ or bupivacaine $0.0625 \%$ plus sufentanil $0.25 \mu \mathrm{g} \cdot \mathrm{mL}(-1)$ : a study in singleton breech presentation. Int J Obstet Anesth 2002; 11: 13-8.

24. Ginosar $Y$, Davidson EM, Firman N, Meroz Y, Lemmens $H$, Weiniger $C F$. A randomized controlled trial using patientcontrolled epidural analgesia with $0.25 \%$ versus $0.0625 \%$ bupivacaine in nulliparous labor: effect on analgesia requirement and maternal satisfaction. Int J Obstet Anesth 2010; 19: 171-8.

25. Khan MA, Pillai A, Dave NM, Kamdar BM. Epidural analgesia during labour-comparison of continuous infusion of $0.125 \%$ bupivacaine V/s $\quad 0.0625 \%$ bupivacaine $/ 0.0001 \%$ fentanyl. J Anaesth Clin Pharmacol 2004; 20: 267-71.

26. James KS, McGrady E, Quasim I, Patrick A. Comparison of epidural bolus administration of $0.25 \%$ bupivacaine and $0.1 \%$ bupivacaine with $0.0002 \%$ fentanyl for analgesia during labour. Br J Anaesth 1998; 81: 507-10.

27. Hemanth Kumar VR, Mishra SK, Rupavani K, Ezhilarasu P, Prabahar $R$. Ultra low concentrations of epidural bupivacaine with fentanyl along with intrathecal fentanyl for labor analgesia. J Anaesthesiol Clin Pharmacol 2009; 25: 293-6.

28. Narayanan $R$, Wahal $R$, Bhushan $S$, Singh V, Das V, Agarwal A. Comparison of two different doses of bupivacaine with sufentanil on ambulatory labour analgesia. J Anaesthesiol Clin Pharmacol 2009; 25: 49-53.

29. Atienzar MC, Palanca JM, Borras R, Esteve I, Fernandez M, Miranda A. Ropivacaine $0.1 \%$ with fentanyl 2 microg $\mathrm{mL}(-1)$ by epidural infusion for labour analgesia. Eur J Anaesthesiol 2004; 21: 770-5.

30. Lee BB, Ngan Kee WD, Lau WM, Wong AS. Epidural infusions for labor analgesia: a comparison of $0.2 \%$ ropivacaine, $0.1 \%$ ropivacaine, and $0.1 \%$ ropivacaine with fentanyl. Reg Anesth Pain Med 2002; 27: 31-6.

31. Gogarten $W$, Van de Velde $M$, Soetens $F$, et al. A multicentre trial comparing different concentrations of ropivacaine plus sufentanil with bupivacaine plus sufentanil for patient-controlled epidural analgesia in labour. Eur J Anaesthesiol 2004; 21: 38-45.

32. Shrestha $C K$, Sharma KR, Shrestha RR. Comparative study of epidural administration of $10 \mathrm{ml}$ of $0.1 \%$ bupivacaine with $2 \mathrm{mg}$ butorphanol and $10 \mathrm{ml}$ of $0.25 \%$ plain bupivacaine for analgesia during labor. JNMA J Nepal Med Assoc 2007; 46: 1-6.

33. Segal $S, S u$, Gilbert $P$. The effect of a rapid change in availability of epidural analgesia on the cesarean delivery rate: a meta-analysis. Am J Obstet Gynecol 2000; 183: 974-8.

34. Cambic CR, Wong CA. Labour analgesia and obstetric outcomes. Br J Anaesth 2010; 105(Suppl 1): i50-60.

35. Zhang $J$, Klebanoff MA, DerSimonian $R$. Epidural analgesia in association with duration of labor and mode of delivery: a quantitative review. Am J Obstet Gynecol 1999; 180: 970-7.

36. Lie KK, Groholt EK, Eskild A. Association of cerebral palsy with Apgar score in low and normal birthweight infants: population based cohort study. BMJ 2010; 341: c4990.

37. Wassen MM, Zuijlen J, Roumen FJ, Smits LJ, Marcus MA, Nijhuis JG. Early versus late epidural analgesia and risk of instrumental delivery in nulliparous women: a systematic review. BJOG 2011; 118: 655-61.

38. Olofsson C, Ekblom A, Ekman-Ordeberg G, Irestedt L. Obstetric outcome following epidural analgesia with bupivacaineadrenaline $0.25 \%$ or bupivacaine $0.125 \%$ with sufentanil-a prospective randomized controlled study in 1000 parturients. Acta Anaesthesiol Scand 1998; 42: 284-92.

39. Hicks JA, Jenkins JG, Newton MC, Findley IL. Continuous epidural infusion of $0.075 \%$ bupivacaine for pain relief in labour. A comparison with intermittent top-ups of $0.5 \%$ bupivacaine. Anaesthesia 1988; 43: 289-92.

40. Li DF, Rees GA, Rosen M. Continuous extradural infusion of $0.0625 \%$ or $0.125 \%$ bupivacaine for pain relief in primigravid labour. Br J Anaesth 1985; 57: 264-70.

41. Rodriguez J, Abboud TK, Reyes A, et al. Continuous infusion epidural anesthesia during labor: a randomized, double-blind comparison of $0.0625 \%$ bupivacaine $/ 0.002 \%$ butorphanol and 0.125\% bupivacaine. Reg Anesth 1990; 15: 300-3.

42. Stoddart AP, Nicholson KE, Popham PA. Low dose bupivacaine/ fentanyl epidural infusions in labour and mode of delivery. Anaesthesia 1994; 49: 1087-90.

43. Ferrante FM, Barber MJ, Segal M, Hughes NJ, Datta S. $0.0625 \%$ bupivacaine with $0.0002 \%$ fentanyl via patient-controlled 
epidural analgesia for pain of labor and delivery. Clin J Pain 1995; 11: 121-6.

44. Ewen A, McLeod DD, MacLeod DM, Campbell A, Tunstall ME. Continuous infusion epidural analgesia in obstetrics. A comparison of $0.08 \%$ and $0.25 \%$ bupivacaine. Anaesthesia 1986; 41: 143-7.

45. Russell $R$, Reynolds $F$. Epidural infusion of low-dose bupivacaine and opioid in labour. Does reducing motor block increase the spontaneous delivery rate? Anaesthesia 1996; 51: 266-73.

46. Noble HA, Enever GR, Thomas TA. Epidural bupivacaine dilution for labour. A comparison of three concentrations infused with a fixed dose of fentanyl. Anaesthesia 1991; 46: 549-52.

47. Beilin Y, Nair A, Arnold I, et al. A comparison of epidural infusions in the combined spinal/epidural technique for labor analgesia. Anesth Analg 2002; 94: 927-32.

48. Lowson SM, Eggers KA, Warwick JP, Moore WJ, Thomas TA. Epidural infusions of bupivacaine and diamorphine in labour. Anaesthesia 1995; 50: 420-2.

49. Chestnut DH, Owen CL, Bates JN, Ostman LG, Choi WW, Geiger $M W$. Continuous infusion epidural analgesia during labor: a randomized, double-blind comparison of $0.0625 \%$ bupivacaine/ $0.0002 \%$ fentanyl versus $0.125 \%$ bupivacaine. Anesthesiology 1988; 68: 754-9.

50. Olofsson CI, Ekblom AO, Ekman-Ordeberg GE, Irestedt LE. Post-partum urinary retention: a comparison between two methods of epidural analgesia. Eur J Obstet Gynecol Reprod Biol 1997; 71: 31-4.

51. Stainthorp SF, Bradshaw EG, Challen PD, Tobias MA. $0.125 \%$ bupivacaine for obstetric analgesia? Anaesthesia 1978; 33: 3-9.

52. Tan S, Reid J, Thorburn J. Extradural analgesia in labour: complications of three techniques of administration. Br J Anaesth 1994; 73: 619-23.

53. Thorburn J, Moir DD. Extradural analgesia: the influence of volume and concentration of bupivacaine on the mode of delivery, analgesic efficacy and motor block. Br J Anaesth 1981; 53: 933-9.

54. Handley $G$, Perkins $G$. The addition of pethidine to epidural bupivacaine in labour-effect of changing bupivacaine strength. Anaesth Intensive Care 1992; 20: 151-5.

55. Moir DD. Proceedings: A clinical trial of four anaesthetics for obstetric epidural analgesia. Scott Med J 1975; 20: 187.

56. Harms C, Siegemund M, Marsch SC, Surbek DV, Hosli I, Schneider MC. Initiating extradural analgesia during labour: comparison of three different bupivacaine concentrations used as the loading dose. Fetal Diagn Ther 1999; 14: 368-74.

57. Paech MJ. Patient controlled epidural analgesia during labour: choice of solution. Int J Obstet Anesth 1993; 2: 65-71.

58. Russell R, Quinlan J, Reynolds F. Motor block during epidural infusions for nulliparous women in labour: a randomized doubleblind study of plain bupivacaine and low dose bupivacaine with fentanyl. Int J Obstet Anesth 1995; 4: 82-8.

59. Scrutton MJ, Porter JS, O'Sullivan G. Comparison of three different loading doses to establish epidural analgesia in labour. Int J Obstet Anesth 1998; 7: 165-9.
60. Cohen SE, Yeh JY, Riley ET, Vogel TM. Walking with labor epidural analgesia: the impact of bupivacaine concentration and a lidocaine-epinephrine test dose. Anesthesiology 2000; 92: 387-92.

61. Christiaens F, Verborgh C, Dierick A, Camu F. Effects of diluent volume of a single dose of epidural bupivacaine in parturients during the first stage of labor. Reg Anesth Pain Med 1998; 23: 134-41.

62. Sanchez-Pereles MC, Uribarri FJ. Epidural analgesia for the delivery work. Use of low doses of bupivacaine associated with fentanile (Spanish). Rev Soc Esp. Dolor 1999; 6: 406-11.

63. Dennison B. Dosage or concentration. Anaesthesia 1990; 45: 885.

64. Dresner $M$, Bamber J, Calow C, Freeman J, Charlton P. Comparison of low-dose epidural with combined spinal-epidural analgesia for labour. Br J Anaesth 1999; 83: 756-60.

65. Elliott RD. Continuous infusion epidural analgesia for obstetrics: bupivacaine versus bupivacaine-fentanyl mixture. Can J Anaesth 1991; 38: 303-10.

66. Lyons GR, Kocarev MG, Wilson RC, Columb MO. A comparison of minimum local anesthetic volumes and doses of epidural bupivacaine $(0.125 \% \mathrm{w} / \mathrm{v}$ and $0.25 \% \mathrm{w} / \mathrm{v})$ for analgesia in labor. Anesth Analg 2007; 104: 412-5.

67. Marcoux S, Mailloux J, Fontaine JY, Leclerc M. Bupivacaine concentration and obstetric delivery. Lancet 1987; 2: 330-1.

68. Wang LZ, Chang XY, Liu X, Hu XX, Tang BL. Comparison of bupivacaine, ropivacaine and levobupivacaine with sufentanil for patient-controlled epidural analgesia during labor: a randomized clinical trial. Chin Med J (Engl) 2010; 123: 178-83.

69. Castro LF, Ferreira RL, Moraes Filho R, Oliveira AS, Serafim $M M$. Infusao continua da associacao de fentanil e bupivacaina em diferentes concentracoes por via peridural no trabalho de parto. Rev Bras Anestesiol 2000; 50: 337-40.

70. Bernard JM, Le Roux D, Frouin J. Ropivacaine and fentanyl concentrations in patient-controlled epidural analgesia during labor: a volume-range study. Anesth Analg 2003; 97: 1800-7.

71. Sia AT, Ruban P, Chong JL, Wong K. Motor blockade is reduced with ropivacaine $0.125 \%$ for parturient-controlled epidural analgesia during labour. Can. J Anesth 1999; 46: 1019-23.

72. Boselli E, Debon $R$, Duflo F, Bryssine B, Allaouchiche B, Chassard D. Ropivacaine $0.15 \%$ plus sufentanil $0.5 \mathrm{microg} / \mathrm{mL}$ and ropivacaine $0.10 \%$ plus sufentanil $0.5 \mathrm{microg} / \mathrm{mL}$ are equivalent for patient-controlled epidural analgesia during labor. Anesth Analg 2003; 96: 1173-7.

73. Beilin Y, Galea M, Zahn J, Bodian CA. Epidural ropivacaine for the initiation of labor epidural analgesia: a dose finding study. Anesth Analg 1999; 88: 1340-5.

74. Brockway MS, Noble D, Tunstall ME. A comparison of $0.08 \%$ and $0.0625 \%$ bupivacaine for continuous epidural analgesia in labour. Eur J Anaesthesiol 1990; 7: 227-34.

75. Nageotte MP, Larson D, Rumney PJ, Sidhu M, Hollenbach K. Epidural analgesia compared with combined spinal-epidural analgesia during labor in nulliparous women. N Engl J Med 1997; 337: 1715-9. 